\title{
COMPETÊNCIAS HUMANAS NA EDUCAÇÃO PROFISSIONAL: PERCEPÇÕES DAS ORGANIZAÇÕES
}

\author{
Liséria Letícia da Silva, Suzana Feldens Schwertner \\ Universidade do Vale do Taquari \\ DOI: 10.15628/rbept.2018.6335
}

Artigo submetido em set/2018 e aceito em out/2018

\begin{abstract}
RESUMO
Muitos são os questionamentos e incertezas que emergem da temática competências humanas na Educação Profissional. A partir deste pressuposto, questiona-se: que importância um grupo de organizações do Vale do Taquari atribui às competências humanas no desempenho das funções dos profissionais de nível técnico? O presente artigo apresenta uma pesquisa que tem o propósito de analisar as competências humanas na educação profissional. Trata-se de uma pesquisa qualiquantitativa construída a partir de um questionário semiestruturado, que foi aplicada a 24 organizações do Vale do Taquari (RS), com o objetivo de verificar o grau de importância que as mesmas atribuem às competências humanas dos profissionais de nível técnico e identificar quais competências humanas essas organizações elencam ser as mais importantes para o profissional de nível técnico. Busca, igualmente, compreender a relação existente entre competências técnicas e competências humanas na visão das organizações. Os resultados evidenciaram que as competências humanas dos profissionais de nível técnico são consideradas importantes para as organizações, mas mais importante é o profissional contemplar em seu perfil competências humanas e técnicas. Relacionamento interpessoal, comunicação, motivação e energia para o trabalho, organização e planejamento foram as competências humanas mais valorizadas pelas organizações. Ao final, destaca-se que a educação profissional deve estar atenta ao mercado e comprometida também com o desenvolvimento de competências humanas.
\end{abstract}

Palavras-Chave: Competências humanas. Educação Profissional. Organizações.

\section{HUMAN COMPETENCES IN PROFESSIONAL EDUCATION: PERCEPTIONS OF ORGANIZATIONS}

\begin{abstract}
There are many questions and uncertainties that emerge from the human competences in professional education. From this assumption, It is inquired: what importance a group of organizations in Vale do Taquari assigns to human competences in technical level professionals to perform tasks? This article presents a research which has the purpose of analyzing human competences in professional education. This is a qualitative-quantitative research constructed from semi structured questionnaire, which was applied to 24 organizations in Vale do Taquari (RS), with the objective of verifying the degree of importance that they assign to the human competences of technical level professionals and identify which human competences these organizations list are the most important for the technical level professional. It also seeks to understand the relationship between technical competences and human competences in the organizations' point of view. The results have exposed the importance of human competences of professionals at the technical level for the organizations, but more importantly, is the professional to contemplate in his profile human and technical competences. Interpersonal relationships, communication, motivation and energy for work, organization and planning were the most valued human competences by the organizations. And so, it is emphasized that professional education should be attentive to the market and also committed to the development of human competences.
\end{abstract}

Keywords: Human Competencies. Professional Education. Organizations.

Vol. 2 (2018) 


\section{INTRODUÇÃO}

As organizações atuais precisam buscar constantemente as melhores estratégias para garantir a sustentabilidade do seu negócio, pois estão inseridas em mercados cada vez mais complexos, competitivos e de grandes transformações. Ter profissionais capacitados e competentes para atuar em um contexto tão instável pode ser um grande diferencial.

É neste momento que, conforme Ruas (2008), surge a noção de competência, como uma forma nova de pensar qual o papel do "trabalho" nas organizações, que não se reduz ao saber (formação educacional ou profissional), nem somente ao saber-fazer (conjunto de conhecimentos adquiridos), mas à capacidade de mobilização e aplicação desses conhecimentos e capacidades numa condição particular e situação específica.

$\mathrm{Na}$ atualidade, as organizações brasileiras exigem cada vez mais a melhoria na capacidade de obter resultados por meio das pessoas. Investimentos em tecnologias de última geração, inovação nas metodologias de trabalho ou melhoria nos processos podem ser realizados por toda e qualquer empresa, mas, para isso, é necessário contar com pessoas competentes.

Uma opção para a formação de profissionais para atuar nesse ambiente está na Educação Profissional, que deve estar cada vez mais distante de uma educação tradicional (fundamentada no poder do verbo, teórica e dependente da memória) e mais próxima de uma aprendizagem significativa, contextualizada, orientada para o uso das tecnologias e recursos da inteligência e que proporcione a geração de competências humanas, como: desenvolver habilidades em solucionar problemas e conduzir projetos nos diversos segmentos organizacionais (BARBOSA; MOURA, 2013).

Segundo Tomasi (2004), em meados do século XX, quando a educação profissional foi concebida, sua finalidade era a de formar profissionais tecnicamente muito bem preparados, o objetivo era organizar a transmissão dos saberes do trabalho e assim qualificar o trabalhador. Entretanto, o mundo do trabalho contemporâneo, citado por Barbosa e Moura (2013), ampliou o horizonte da educação profissional e fez surgir a necessidade do desenvolvimento de valores e competências humanas em seus estudantes (relacionamento interpessoal, trabalho em equipe, capacidade de iniciativa, criatividade, flexibilidade, autocontrole, comunicação...), que passaram a integrar a educação profissional dos dias de hoje.

Contudo, abordar o tema competências humanas na Educação Profissional não é nada corriqueiro, visto a complexidade que envolve o significado e entendimento da palavra "competência". Depresbiteris (2005) relata que a polissemia do termo aliada às diferentes visões políticas e filosóficas contribuiu para que a noção de competência fosse vista como um enigma para os educadores. Em contrapartida, a proposta de se trabalhar competências na 
Educação Profissional foi formalizada no Brasil com a Lei de Diretrizes e Bases da Educação Nacional - LDB, Lei no 9394 (BRASIL, 1996), que dedica um capítulo especial para a Educação Profissional. Em seu Art. 39 cita que a educação profissional, ao ser integrada aos diferentes níveis e modalidades de educação, ao trabalho, à ciência e à tecnologia, conduz ao desenvolvimento de aptidões para a vida produtiva, ou seja, faz surgir a necessidade de mobilizar outras dimensões dos saberes.

Envolver-se em uma articulação da evolução do ensino, trabalhando em prol do desenvolvimento de competências humanas dos seus alunos, poderá trazer resultados significativos para a educação profissional e, por conseguinte, para a instituição de ensino que a represente. Entender as demandas do mercado no que se refere a conhecimentos, habilidades e atitudes dos profissionais que nele atuam e contribuir com o desenvolvimento dessas competências (técnicas e humanas) de forma integral poderá ser um diferencial e resultar em um grande avanço para a educação profissional.

Dentro desse contexto, tornou-se fundamental para as organizações definirem quais competências humanas são importantes e que devem fazer parte do perfil profissional de seus funcionários para o sucesso dos seus negócios. Entretanto, será que gestores reconhecem a importância das competências para o sucesso das suas organizações? Há um entendimento de quais competências humanas agregam valor para o resultado das organizações? Essas competências são identificadas, divulgadas e desenvolvidas? Em um processo de seleção as organizações buscam pessoas com determinadas competências humanas? Muitos são os questionamentos e incertezas que emergem da temática competências humanas, porém precisamos conhecer e estar inseridos neste meio, para então trabalhar e desenvolver tais competências na educação profissional. A partir deste pressuposto, e pensando sobre o olhar das organizações, passamos a perguntar: que importância um grupo de organizações do Vale do Taquari atribui às competências humanas no desempenho das funções dos profissionais de nível técnico?

A presente pesquisa visa analisar o grau de importância das competências humanas que contemplam o profissional de nível técnico em organizações do Vale do Taquari. Busca-se com o estudo: verificar o grau de importância que as organizações atribuem às competências humanas dos profissionais de nível técnico; identificar quais competências humanas um grupo de organizações do Vale do Taquari elencam ser as mais importantes para o profissional de nível técnico, além de compreender a relação existente entre competências técnicas e competências humanas.

Para realização desta investigação, organizou-se uma pesquisa qualiquantitativa construída a partir de um questionário semiestruturado respondido por 24 organizações para discutir o tema competências humanas e sua importância tanto para as organizações quanto para a formação e desenvolvimento dos profissionais de nível técnico e, consequentemente, para as Instituições de Educação Profissional Técnica. 
A escolha desse tema justifica-se pela necessidade que as organizações possuem em buscar no mercado de trabalho pessoas com competências humanas desenvolvidas e que possam contribuir com o desenvolvimento organizacional. Ao passo que as competências humanas possam se alinhar com as competências e estratégias organizacionais, a organização estará mais fortalecida e propensa a alcançar melhores resultados. A pesquisa trouxe informações relevantes que contribuem com a importância do tema estabelecido, assim como esclareceu que competências técnicas e humanas precisam ser desenvolvidas em conjunto. Com essas informações foi possível conhecer o perfil de competências humanas que as organizações do Vale do Taquari consideram mais relevantes para um profissional de nível técnico.

É imprescindível reconhecer, através das organizações, quais são as competências que devem ser estimuladas em sala de aula com a finalidade de formar um profissional que se aproxime mais do perfil de competências sinalizado pelo mercado de trabalho, já que o desempenho de uma organização depende de um conjunto de decisões tomadas pela competência de seus profissionais. Dessa forma, as Instituições de Educação Profissional poderão se valer das informações da pesquisa e investir no aprimoramento do ensino de Nível Técnico.

\section{EXPLORANDO O CONCEITO COMPETÊNCIA HUMANA}

As organizações precisam manter-se em constante desenvolvimento, em decorrência dos processos de globalização, da turbulência econômica, exigências de renovação, adaptação e maior valor agregado dos produtos e serviços, assim como das relações comerciais (DUTRA, 2008). Boterf (2003, p.17), argumenta que a capacidade de inovação não reside mais exclusivamente no potencial industrial ou nas despesas de pesquisa e desenvolvimento, mas no investimento nos "recursos raros" que chamamos de competências. Gerenciar o capital humano, investir em inteligência, renovar os conhecimentos e competências e manter-se em situação de aprendizagem permanente, passa a ter um papel de destaque nas organizações que estão inseridas em uma "economia da variedade", que exige inovação, renovação e adaptação de dos produtos e serviços. Dutra (2008) ressalta que ter pessoas autônomas, com maior iniciativa e comprometidas com os objetivos e estratégias organizacionais, reflete um diferencial competitivo para as organizações.

Para desenvolver-se como empresa, é indispensável investir em conhecimentos e competências, o que coloca as organizações em situações de aprendizagem permanente. Porém, antes de continuar o relato de que as competências contribuem para o diferencial competitivo das organizações, é preciso entender o conceito de competência. O que é competência então? Ao tentar responder a essa pergunta, deparamo-nos com um conceito "complexo e multifacetado" (BRANDÃO; ANDRADE, 2007, p.38), tal é a diversidade das interpretações do termo ao longo dos últimos anos. Fleury e Fleury (2008) relatam 
que desde a década de 70 , o tema competência vinha sendo pesquisado por psicólogos e educadores, contudo nos últimos anos também entrou para as discussões acadêmicas e organizacionais, abrangendo diferentes compreensões: em termos das pessoas (as competências do indivíduo), das organizações (as competências essenciais) e dos países (sistemas educacionais e capacitação profissional).

As definições de competências são variadas, porém há alguns pontos convergentes no que se refere às contribuições das pessoas como diferenciais nos resultados organizacionais. Vejamos abaixo os conceitos que fundamentam a afirmação de Gramigna (2007, p.2):

Tabela 1: Conceituando competências

\begin{tabular}{l|l}
\hline \multicolumn{1}{c|}{ Autor } & \multicolumn{1}{c}{ Conceito Competências } \\
\hline $\begin{array}{l}\text { Levy Leboyer } \\
\text { (1997) }\end{array}$ & $\begin{array}{l}\text { Repertórios de comportamentos que algumas pessoas ou } \\
\text { organizações dominam melhor que outras, tornando-as } \\
\text { eficazes e competitivas em determinadas situações. }\end{array}$ \\
\hline Montmollin (1984) & $\begin{array}{l}\text { Conjunto de saberes, práticas, comportamentos, } \\
\text { procedimentos e tipo de raciocínio que se pode acessar em } \\
\text { um novo aprendizado. }\end{array}$ \\
\hline $\begin{array}{l}\text { Gilbert e Parlier } \\
\text { (1991) }\end{array}$ & $\begin{array}{l}\text { É o conjunto de conhecimentos, capacidade de ação e } \\
\text { comportamentos estruturados, colocados à disposição de um } \\
\text { objetivo ou meta, na busca de resultados. }\end{array}$ \\
\hline $\begin{array}{l}\text { Valerie Marback } \\
\text { (1998) }\end{array}$ & $\begin{array}{l}\text { Um conjunto de elementos que estão em interação dinâmica e } \\
\text { fazem o diferencial de uma organização ou pessoa. São os } \\
\text { saberes (conhecimento) o saber-fazer (habilidades), os } \\
\text { comportamentos (atitudes) e as faculdades cognitivas } \\
\text { (qualidades pessoais). }\end{array}$ \\
\hline
\end{tabular}

Fonte: Elaborado pelas autoras a partir de Gramigna (2007, p.2).

$\mathrm{Na}$ construção de um conceito próprio, Fleury e Fleury (2004, p. 30) definem a competência como "[...] um saber agir responsável e reconhecido, que implica mobilizar, integrar, transferir conhecimentos, recursos, habilidades, que agregam valor econômico à organização e valor social ao indivíduo". Os autores examinam mais detalhadamente este conceito, propondo algumas definições, conforme segue:

Saber agir: saber o que e porque faz; saber julgar, escolher, decidir. Saber mobilizar: saber mobilizar recursos de pessoas, financeiros, materiais criando sinergia entre eles. Saber comunicar: compreender, processar, transmitir informações e conhecimentos, assegurando o entendimento da mensagem pelos outros. Saber aprender: trabalhar o conhecimento e a experiência; rever modelos mentais; saber desenvolver-se e propiciar o desenvolvimento dos outros. Saber comprometer-se: saber engajar-se e comprometerse com os objetivos da organização. Saber assumir 
responsabilidades: ser responsável assumindo os riscos e as consequências de suas ações e ser, por isso, reconhecido. Ter visão estratégica: conhecer e entender o negócio da organização, seu ambiente, identificando oportunidades e alternativas (FLEURY; FLEURY, 2004, p. 31).

Seguindo a mesma linha de "mobilização dos saberes", Boterf (2003, p.38) argumenta que as competências de um profissional estão atreladas a sua capacidade de saber administrar uma situação profissional complexa, no que tange mobilizar os seguintes saberes: saber agir e reagir com pertinência, saber combinar recursos e mobilizá-los, saber transpor, saber aprender e aprender a aprender e por último saber envolver-se.

Gramigna (2007) também faz referência aos saberes e relata que uma competência pode ser observada no dia a dia e no trabalho. A mesma autora, na definição das competências, observa que elas podem ser desdobradas em três blocos: o primeiro refere-se às habilidades do indivíduo, conceituadas como a capacidade de colocar seus conhecimentos em ação, para gerar resultados, envolve o domínio de técnicas, talentos e capacidades (saber fazer); o segundo bloco está relacionado com os conhecimentos, refere-se às informações, fatos, procedimentos e conceitos (saber) e o último bloco envolve as atitudes, contemplando valores, princípios, comportamentos, pontos de vista, opiniões, percepções e atos pessoais (querer).

Nessa conjuntura de saberes, é preciso ressaltar que a estratégia de operação e a imagem que o profissional tem de si mesmo são fatores que irão determinar e mobilizar de forma pertinente um conjunto de saberes, habilidades, aptidões, qualidades pessoais e experiências. Escolhê-los e combiná-los em relação aos objetivos (problemas, projetos, atividades) é uma das características essenciais da competência de um bom profissional (BOTERF, 2003).

Em se tratando das competências dos indivíduos, estabelecemos aqui referência às competências humanas. Para Tomasi (2004), as competências humanas são únicas e pertencem a uma categoria formalizada, elas não podem ser encontradas em todos os indivíduos como também não são uma característica individual. As competências humanas dizem respeito ao uso de técnicas definidas, utilizadas e adaptadas pelos indivíduos às novas situações, estão associadas à execução de tarefas complexas, organizadas e que exigem uma atividade intelectual importante.

Lerner (2002, p. 54) associa a importância das competências humanas com o resultado de uma organização. Segundo o autor, as competências humanas devem ser colocadas no "centro do negócio", a fim de poder desempenhar uma função catalisadora no processo de planejamento e gestão estratégica da empresa. Para o autor:

A orientação para competências humanas é o ponto de partida para que a empresa possa praticar uma gestão voltada aos interesses do mercado visando obter uma base de clientes satisfeitos e fiéis que serão os responsáveis pela sobrevivência e prosperidade dos negócios (LERNER, 2002, p. 54). 
No mesmo sentido, para definir competências humanas, Zarifian (2001) as associa com situações profissionais e enfatiza que as competências não se limitam aos conhecimentos teóricos e empíricos construídos pelo indivíduo. Para ele, competência é a inteligência prática de situações que se apoiam sobre os conhecimentos adquiridos e os transformam conforme a intensidade e complexidade das situações. Para Zarifian (2001, p. 68-69), a competência é:

[...] o tomar iniciativa e assumir responsabilidades do indivíduo diante de situações profissionais com as quais se depara. [...] Tomar iniciativa é uma ação que modifica algo que existe, que introduz algo novo, que começa alguma coisa, que cria.

Essa definição introduz dois novos quesitos ao conceito de competência: a necessidade de uma iniciativa por parte do profissional e a consciência de sua responsabilidade com as situações impostas por seu trabalho. $O$ indivíduo competente não pode ser apático diante das situações, não pode responder automaticamente e da mesma forma a situações diferenciadas. Além disso, ao tomar iniciativa, pressupõe uma atitude proativa do profissional, agindo antes mesmo que a situação se apresente.

Boterf (2003) reforça esse entendimento de troca na aquisição de competências, ressaltando que o desenvolvimento de competências depende fundamentalmente da motivação do indivíduo para aprender, do sistema educacional disponível e do ambiente de trabalho que estimule a aprendizagem. Nesse contexto, Brandão (2007) ressalta quão importante é para as organizações o desenvolvimento de sistemas educacionais não apenas alinhados às estratégias organizacionais, mas que contemplem igualmente as necessidades de aprendizagem dos funcionários.

Seguindo com nosso propósito de explorar o conceito competência, entramos na dimensão organizacional que trata das competências essenciais, noção desenvolvida por Hamel e Prahalad (1995). As competências essenciais são aquelas que diferenciam a organização perante concorrentes e clientes, constituindo a razão da sua sobrevivência. Referenciando a abrangência dessas competências, Ruas (2008) afirma que elas devem estar presentes em todas as áreas, grupos e pessoas da organização, entretanto em níveis estratégicos diferenciados.

Conforme Hamel e Prahalad (1995), para serem essenciais as competências das organizações deveriam obedecem a três critérios: oferecer aos consumidores benefícios reais, serem difíceis de imitar (pois se tornam 0 diferencial da empresa) e dar acesso a diferentes mercados. Ao definir sua estratégia competitiva, a organização identifica suas competências essenciais ao negócio e as competências necessárias para o desempenho de cada função, o que chamamos de competências organizacionais.

Vale ressaltar a importância de definir competências para o desempenho de cada função, mencionada aqui por Fleury e Fleury (2008), que retratam a relação sistêmica do indivíduo com a organização. Segundo os referidos autores, ao passar do nível estratégico de formação de competências organizacionais para o 
nível das competências do indivíduo, é possível classificar competências em três categorias: competências técnicas profissionais são relacionadas a competências específicas, para uma operação, ocupação ou tarefa; já as competências sociais são as caracterizadas como necessárias para interagir com as pessoas e por último as competências de negócio relacionadas à compreensão do negócio, seus objetivos, clientes, concorrentes, ambiente social e político.

Para auxiliar as organizações na definição de competências de seus funcionários, ou seja, para definir competências humanas e servir de base para programas de Gestão por Competências, Gramigna (2007 p.44) elencou um rol de quinze competências mais requisitadas no mercado brasileiro. Seu levantamento foi realizado entre os anos de 1997 até 2005. No esquema a seguir, percebemos as distintas capacidades destacadas pela autora:

Tabela 2 - Competências de Gramigna (2007)

\begin{tabular}{|c|c|c|}
\hline № & Competência & Descrição \\
\hline 1 & $\begin{array}{l}\text { Capacidade } \\
\text { empreendedora }\end{array}$ & $\begin{array}{l}\text { Facilidade para identificar novas oportunidades de ação, } \\
\text { propor e implementar soluções para os problemas e } \\
\text { necessidades que se apresentam de forma assertiva, } \\
\text { inovadora e adequada. }\end{array}$ \\
\hline 2 & $\begin{array}{l}\text { Capacidade de } \\
\text { trabalhar sob } \\
\text { pressão }\end{array}$ & $\begin{array}{l}\text { Capacidade para selecionar alternativas de forma perspicaz } \\
\text { e implementar soluções tempestivas diante de problemas } \\
\text { identificados, considerando suas prováveis consequências. }\end{array}$ \\
\hline 3 & Comuni & $\begin{array}{l}\text { Capacidade de ouvir, processar e compreender o contexto } \\
\text { da mensagem, expressar-se de diversas formas e } \\
\text { argumentar com coerência usando o feedback de forma } \\
\text { adequada, facilitando a iteração entre as partes. }\end{array}$ \\
\hline 4 & Criatividade & $\begin{array}{l}\text { Capacidade para conceber soluções inovadoras viáveis e } \\
\text { adequadas às situações apresentadas. }\end{array}$ \\
\hline 5 & $\begin{array}{l}\text { Cultura da } \\
\text { qualidade }\end{array}$ & $\begin{array}{l}\text { Postura orientada para a busca contínua da satisfação das } \\
\text { necessidades e superação das expectativas dos clientes } \\
\text { internos e externos. }\end{array}$ \\
\hline 6 & $\begin{array}{l}\text { Dinamismo, } \\
\text { iniciativa }\end{array}$ & $\begin{array}{l}\text { Capacidade para atuar de forma proativa e arrojada diante } \\
\text { de situações diversas. }\end{array}$ \\
\hline 7 & Flexibilidade & $\begin{array}{l}\text { Habilidade para adaptar-se oportunamente às diferentes } \\
\text { exigências do meio, sendo capaz de rever sua postura } \\
\text { perante argumentações convincentes. }\end{array}$ \\
\hline 8 & Liderança & $\begin{array}{l}\text { Capacidade para catalisar os esforços grupais de forma a } \\
\text { atingir ou a superar os objetivos organizacionais, } \\
\text { estabelecendo um clima motivador, formando parcerias e } \\
\text { estimulando o desenvolvimento da equipe. }\end{array}$ \\
\hline 9 & $\begin{array}{l}\text { Motivação: } \\
\text { energia para o }\end{array}$ & $\begin{array}{l}\text { Capacidade de demonstrar interesse pelas atividades que } \\
\text { vai executar, tomando iniciativas e mantendo atitude de } \\
\text { disponibilidade. Apresentar postura de aceitação e tônus }\end{array}$ \\
\hline
\end{tabular}




\begin{tabular}{l|l|l} 
& trabalho & muscular que indica energia para o trabalho. \\
\hline 10 & Negociação & $\begin{array}{l}\text { Capacidade de expressar e ouvir o outro, buscando o } \\
\text { equilíbrio de soluções satisfatórias nas propostas } \\
\text { apresentadas pelas partes quando há conflitos de } \\
\text { interesse. Observa o sistema de trocas que envolve o } \\
\text { contexto. }\end{array}$ \\
\hline 11 & Organização & $\begin{array}{l}\text { Capacidade de organizar as ações de acordo com o } \\
\text { planejado, de forma a facilitar a execução. }\end{array}$ \\
\hline 12 & Planejamento & $\begin{array}{l}\text { Capacidade para planejar o trabalho, atingindo resultados } \\
\text { por meio do estabelecimento de prioridades, metas } \\
\text { tangíveis, mensuráveis e dentro de critérios de } \\
\text { desempenho válidos. }\end{array}$ \\
\hline 14 & $\begin{array}{l}\text { Relacionamento } \\
\text { interpessoal }\end{array}$ & $\begin{array}{l}\text { Habilidade para interagir com as pessoas de forma } \\
\text { empática, inclusive diante de situações conflitantes, } \\
\text { demonstrando atitudes positivas, comportamentos maduros } \\
\text { e não combativos. }\end{array}$ \\
\hline 15 & $\begin{array}{l}\text { Capacidade para selecionar alternativas de forma } \\
\text { decisão }\end{array}$ & $\begin{array}{l}\text { Sistematizada e perspicaz, obtendo e implementando } \\
\text { soluçes adequadas diante de problemas identificados, } \\
\text { considerando limites e riscos. }\end{array}$ \\
\hline Fasmica & $\begin{array}{l}\text { Capacidade para perceber a integração e interdependência } \\
\text { das partes que compõem o todo, visualizando tendências e } \\
\text { possíveis ações capazes de influenciar o futuro. }\end{array}$ \\
\hline
\end{tabular}

Fonte: Elaborado pelas autoras a partir de Gramigna (2007).

Em face do exposto, as organizações necessitam de profissionais competentes, pessoas aptas a mobilizar seus conhecimentos com habilidade e atitude de fazer frente aos imprevistos. Colocando organização e pessoas lado a lado, verifica-se um processo contínuo de troca de competências. A organização transfere seu patrimônio para as pessoas, enriquecendo-as e preparando-as para enfrentar novas situações profissionais e pessoais. As pessoas, ao desenvolverem sua capacidade individual, transferem para a organização seu aprendizado, capacitando a organização para enfrentar novos desafios (DUTRA, 2008).

Quando associamos o termo competência com capacidades, conhecimentos e aprendizado, estamos também entrando na esfera da educação, ambiente onde o processo de aprendizagem acontece quando provoca mudanças nos processos de pensar e agir de uma pessoa. Depresbiteris (2005) e Perrenoud (1999) afirmam que a primeira ideia de competência na educação estava relacionada com a competitividade, advinda da necessidade do trabalhador e organizações competirem por um lugar no mercado, em tempos de crise. Da mesma forma, na educação profissional, o termo competência tem sido utilizado para definir um conjunto de recursos a serem mobilizados para enfrentar uma situação complexa. 
O surgimento do termo "competência" na Educação Profissional, segundo estudos de Depresbiteris (2005), ocorreu em alguns países industrializados que apresentavam maiores problemas em integrar seus sistemas educativos e produtivos. O setor produtivo sofria mudanças no mundo de trabalho e sinalizava a necessidade de um novo perfil do trabalhador, foi então que o modelo de competências surgiu como uma proposta para a educação profissional. Era preciso uma formação mais ampla do trabalhador e as organizações passaram a buscar no mercado profissionais com maior autonomia, iniciativa e capacidade de solucionar problemas.

O Parecer do Conselho Nacional de Educação CNE/CEB nำ 16/1999 (BRASIL, 1999, texto digital, que trata das Diretrizes Curriculares Nacionais para a Educação Profissional de Nível Técnico e que regulamenta a LDB/1996, informa em seu Art. 6º , entendimento do termo competência: "a capacidade de mobilizar, articular e colocar em ação valores, conhecimentos e habilidades necessárias ao desempenho eficiente e eficaz de atividades requeridas pela natureza do trabalho". Passado algum tempo, o parecer CNE/CEB № 11/2012 (BRASIL, 2012) faz alusão para a necessidade do ensino profissionalizante contemplar o desenvolvimento de competências ao mencionar que ele propicie ao trabalhador 0 desenvolvimento de conhecimentos, saberes e competências.

As mudanças constantes no mercado de trabalho conduzem também mudanças no perfil profissional: as Instituições de Educação Profissional precisam investir na estruturação de seus currículos e definir meios para facilitar o desenvolvimento de competências nos seus alunos. As competências devem ser formuladas em consonância com o perfil profissional de conclusão do curso, contemplando os conhecimentos, as habilidades e as atitudes necessárias para o desempenho das atividades do profissional técnico. Tomemos por base a Resolução CNE/CEB no 6, de 20/09/2012 (BRASIL, 2012, texto digital), que define Diretrizes Curriculares Nacionais para a Educação Profissional Técnica, que traz em seu Art. 6o os princípios da Educação Profissional Técnica e os correlaciona com a importância de contemplar nos perfis profissionais de conclusão de curso, o conjunto de: "XV [...] conhecimentos, competências e saberes profissionais requeridos pela natureza do trabalho, pelo desenvolvimento tecnológico e pelas demandas sociais, econômicas e ambientais".

A mesma resolução (BRASIL, 2012), trata da organização curricular dos currículos de Educação Profissional. Nele consta que as escolas de Educação Profissional Técnica devem proporcionar recursos para que os alunos exerçam sua profissão com competência:

\footnotetext{
Art.14[...]

III - recursos para exercer sua profissão com competência, idoneidade intelectual e tecnológica, autonomia e responsabilidade, orientados por princípios éticos, estéticos e políticos, bem como compromissos com a construção de uma sociedade democrática (BRASIL, 2012).
} 
Ao considerar o desenvolvimento de competências na Educação Profissional, é preciso pensar em formas de flexibilizar a educação, desenvolvendo processos de ensino com vistas às exigências que o mundo moderno impõe às organizações, minado de incertezas e mudanças constantes. A educação profissional precisa estar articulada em prol de fomentar 0 desenvolvimento de capacidades para gerar competências tidas como importantes para o mercado de trabalho, contemplando em seus planos o que a legislação estabelece, com um olhar voltado para a sociedade e o meio em que está inserida, sem deixar de lado os desejos, crenças e valores dos seus alunos.

Contudo, antes de tentar operacionalizar o desenvolvimento de competências na educação profissional há de se ter consciência de que o desenvolvimento de competências se adquire na prática, em situações complexas, envolvendo problemas que exigem a mobilização e a busca de saberes para a sua resolução. Ruas (2008, p. 250) defende que o conhecimento, um dos principais recursos da competência, deve estar apoiado em processos de formação das pessoas. $O$ autor argumenta que os processos de formação da atualidade já estão enriquecidos com inovações importantes, como experiências e simulações em sala de aula, o que tem gerado avanços no "saber-fazer" e até mesmo contemplando o "saber-ser"; contudo, essas práticas não parecem ser suficientes para desenvolver competências.

Kuller (2013) nos faz refletir sobre a necessidade de considerar que a aprendizagem de toda a competência humana está fundamentada em um desenvolvimento humano integral, ou seja, é preciso desenvolver-se como pessoa baseado em um esforço contínuo de análise e crescimento pessoal. Conforme o autor, a educação profissional poderá ser considerada uma educação voltada ao desenvolvimento de competências quando estiver voltada ao desenvolvimento integral e permanente dos seus alunos como pessoas e cidadão, independente do perfil profissional ou do curso.

Podemos dizer que as mudanças no que se refere ao aumento da complexidade do trabalho fez com que as organizações atuais pudessem empregar diferentes formas de caracterizar as competências. Uma tendência que se observa é que as competências são caracterizadas como contribuição das pessoas para que a organizações possam interagir com seu ambiente, mantendo ou ampliando suas vantagens competitivas. Entender um pouco mais dessa relação competências - organizações - educação profissional está descrita a seguir, através da aplicação metodológica desta investigação.

\section{METODOLOGIA}

Diante do objeto de estudo, a metodologia consiste em uma abordagem quali-quantitativa de pesquisa. Quantitativa, pois a coleta de dados é estruturada, a análise dos dados é estatística (dados podem ser quantificados) e os resultados podem ser generalizados para a população-alvo, recomendando uma linha de 
ação final. Qualitativa por entender que as análises e reflexões que são construídas nos discursos, subsidiando o pesquisador nas percepções, sentidos e significados das compreensões dos sujeitos pesquisados a respeito das competências (CHEMIN, 2015).

Quanto aos objetivos, é uma pesquisa descritiva, pelo fato de expor as características de determinada população, neste caso, da percepção dos profissionais de Recursos Humanos ou dos Gestores de organizações quanto às competências humanas dos profissionais de nível técnico, obtidas através de um levantamento de dados oriundo da aplicação de um questionário. Andrade (2003) e Barros e Lehfeld (2000) destacam a pesquisa descritiva como sendo aquela em que os fatos são observados, registrados, analisados, classificados e, por fim, interpretados sem haver a intervenção do pesquisador. É utilizada com a finalidade de saber a frequência que um fato acontece, suas características e causas, sendo realizada por meio de coleta de dados.

Quanto aos meios, a pesquisa classifica-se em bibliográfica, uma vez que a fundamentação teórica foi obtida por meio de estudos com base em material publicado em livros, artigos científicos, revistas especializadas, e sites na internet. Também é classificada como de levantamento, pois constituiu-se pela interrogação direta das pessoas (profissionais de Recursos Humanos das organizações ou Gestores), das quais desejava-se conhecer opiniões e relevância sobre $\mathrm{o}$ assunto competências humanas. Em seguida, mediante análise qualiquantitativa, pode se obter as conclusões relacionadas aos dados coletados.

A população alvo são 24 organizações do Vale do Taquari/RS ${ }^{1}$, representadas na pesquisa pelos seus profissionais da área de Recursos Humanos ou pelos Gestores diretos da organização, que se posicionaram sobre a importância das competências humanas em profissionais de Nível Técnico.

Para a coleta de dados, um questionário contendo oito questões abertas e fechadas foi enviado por meio eletrônico para um grupo de 107 organizações do Vale do Taquari (Rio Grande do Sul). O questionário foi elaborado através do recurso Google Formulários ${ }^{2}$, que permite agilidade, confidencialidade e coleta precisa dos dados. Também as respostas foram coletadas de forma organizada e automática, com geração de informações e gráficos para tratamento em planilhas eletrônicas. As três primeiras questões estavam relacionadas a caracterização das

\footnotetext{
${ }^{1}$ O Vale do Taquari é uma região formada por 36 municípios. Está localizado na Região Central do Rio Grande do Sul e fica em média 150 quilômetros de Porto Alegre. Ocupa uma área de 4.826,7 $\mathrm{km}^{2}$ de área ( $1,79 \%$ da área do RS), onde vivem 356.002 pessoas ( $3,14 \%$ da população do RS dados FEE/RS 2016). Nos pequenos municípios se destaca o setor da agropecuária, enquanto nos municípios maiores sobressaem-se atividades ligadas à indústria e ao setor de serviços e comércio. A região é celeiro de milhares de empresas, e abre espaço tanto para grandes como para pequenas e micro se desenvolverem. Disponível em: http://www.fee.rs.gov.br/perfilsocioeconomico/coredes.

${ }^{2}$ Ferramenta que permite a criação de formulários, em meio eletrônico, personalizados para pesquisa e questionários, permite um facilitado compartilhamento com o público alvo através do website, ou via Google+, Facebook ou Twitter. Disponível em: https://gsuite.google.com.br/int//ptBR/products/forms/.
} 
organizações, sendo elas: Segmento da organização, Número de funcionários e Cargo de quem respondeu o questionário. As demais questões relacionavam-se os profissionais de nível técnico e as competências humanas, buscando responder aos objetivos propostos. Os questionamentos foram: "1. A organização possui em seu quadro de funcionários profissionais com titulação Técnica/Profissional (em formação ou titulados)?"; "2. Se a resposta da questão anterior for "sim", cite quais são as titulações destes profissionais;" "3. Classifique cada competência relacionada conforme o grau de importância que sua Organização atribui a um profissional com Titulação de Nível Técnico;" "4. No rol de competências listadas, selecione cinco que na sua opinião deveriam fazer parte do perfil de um bom profissional de Nível Técnico" (na questão 4 e 5 as competências relacionadas foram as competências citadas na Tabela 2) e a última questão, " 5 . Ao avaliar o perfil dos profissionais de Nível Técnico, defina o grau de importância que você dá para as competências abaixo (considere no somatório o percentual de 100\%). Comente sua resposta".

\section{RESULTADOS E DISCUSSÕES}

Do total de 107 questionários enviados para algumas organizações do Vale do Taquari/RS, obteve-se o retorno de 24 questionários, correspondendo a $22,43 \%$ do total da amostra. Percentual de retorno considerado acima da média, se comparado com percentual de $15 \%$, que segundo Malhotra (2006) é o normal de retornos para questionários enviados por meio eletrônico. Dentre as organizações que fizeram parte deste estudo, é possível caracterizá-las conforme o segmento a que pertencem: $66,7 \%$ Indústria, $25 \%$ Serviços e $8,3 \%$ Comércio. Validando o público alvo, obtivemos 17 questionários (70,84\%) respondidos por cargos voltados à área de Recursos Humanos e sete $(29,16 \%)$ advindos da área de Gestão (Diretor, Gerente, Sócio). Todas as organizações que responderam possuem em seu quadro funcionários profissionais de Nível Técnico de diversas áreas, como: Técnico em Administração, Segurança do Trabalho, Recursos Humanos, Alimentos, Química, Contabilidade, Enfermagem, Mecânico, Vendas, Automação Industrial, Meio Ambiente, Agrícola, Turismo, Secretariado, Eletromecânico, Elétrica, Tecnologia da Informação, e Informática.

As organizações participantes desta pesquisa, ao serem questionadas sobre o perfil de competências ideal para um bom profissional de nível técnico, levando em consideração o grau de importância das competências técnicas e humanas, assim posicionaram-se: $33,34 \%$ das organizações consideraram mais importante deter competências humanas contra $12,5 \%$ que consideram mais importantes possuir competências técnicas. Contudo, ter um equilíbrio entre competências é importante para a maioria, representando $54,16 \%$ das organizações, que consideraram competências técnicas e humanas igualmente importantes. A Figura 1 ilustra o resultado: 
Figura 1: Grau de importância das competências

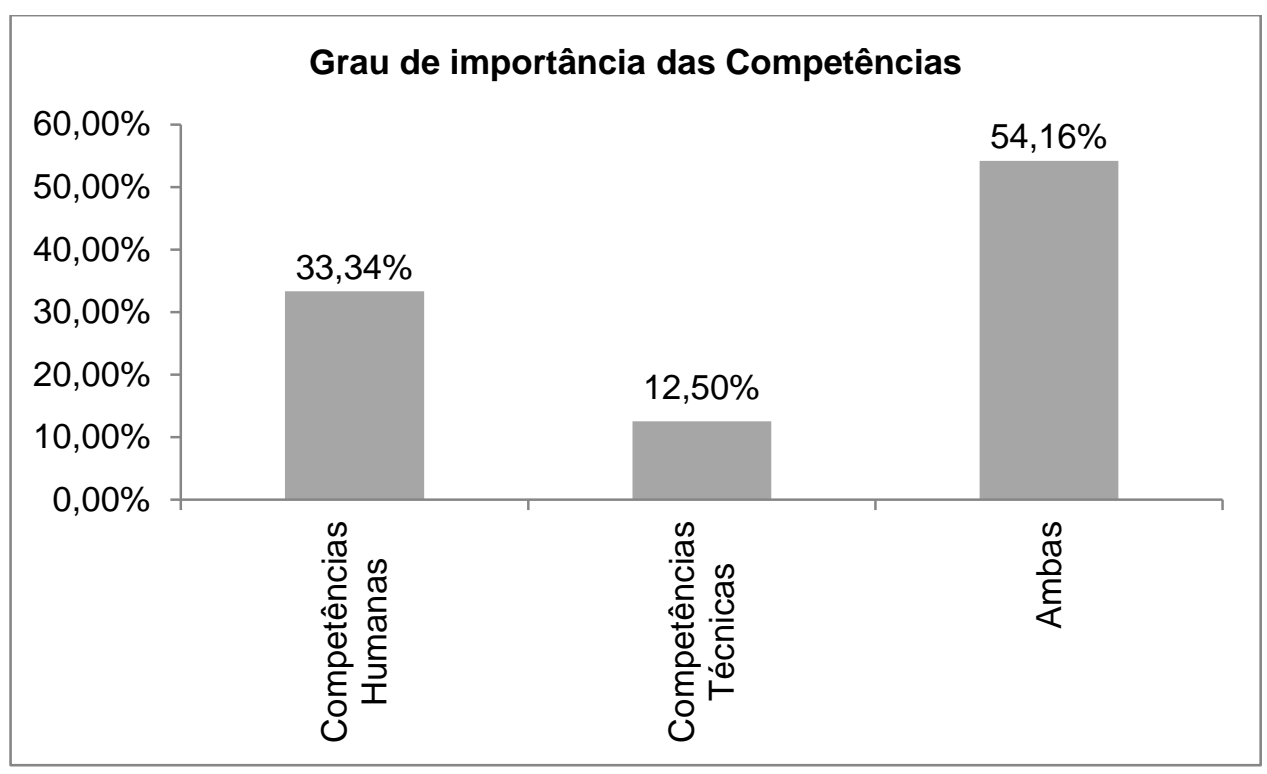

Fonte: Elaborado pelas autoras.

Em uma análise qualitativa da percepção de que competências técnicas e humanas se complementam, podemos citar algumas considerações feitas pelos participantes da pesquisa: "considero a competência humana tão importante quanto a técnica" relatou o participante $(\mathrm{O} 3)^{3}$; seguindo na mesma linha, um gestor relatou a necessidade de haver um equilíbrio entre as competências "ambas devem andar em paralelo e manter-se em constante desenvolvimento" (O16). A presença de competências humanas, tais como: saber trabalhar em equipe, se comunicar com os colegas e ser flexível, foram reforçadas pelo relato de um participante, que argumenta: "de nada adianta ter conhecimento técnico se o colaborador não sabe trabalhar em equipe, se comunicar com os colegas e ser flexível aos acontecimentos diários"(O22). Para finalizar, podemos nos valer do depoimento de um participante e afirmar que "o equilíbrio das competências é essencial" (O20).

Entender que as organizações exigem cada vez mais dos profissionais no que tange às competências complementares à sua formação e habilidades técnicas (DADOY, 2004) nos faz querer conhecer o grau de importância que as organizações atribuem às competências humanas dos profissionais de nível técnico. Baseadas nas quinze competências mais requisitadas no mercado brasileiro, segundo Gramigna (2007), as organizações posicionaram-se conforme Tabela 3:

\footnotetext{
${ }^{3}$ Para manter o anonimato dos representantes das organizações participantes, iremos a partir deste momento, apresentá-los com a seguinte denominação O1, O2 e assim sucessivamente.
} 
Tabela 3: Classificação do grau de importância das competências humanas

\begin{tabular}{|c|c|c|c|c|}
\hline $\begin{array}{l}\text { Competência } \\
\text { Humana }\end{array}$ & $\begin{array}{c}\text { Muito } \\
\text { Importante }\end{array}$ & Importante & $\begin{array}{c}\text { Pouco } \\
\text { Importante }\end{array}$ & $\begin{array}{c}\text { Sem } \\
\text { Importância }\end{array}$ \\
\hline $\begin{array}{l}\text { Relacionamento } \\
\text { interpessoal }\end{array}$ & $83 \%$ & $17 \%$ & $0 \%$ & $0 \%$ \\
\hline $\begin{array}{l}\text { Motivação: energia } \\
\text { para o trabalho }\end{array}$ & $83 \%$ & $17 \%$ & $0 \%$ & $0 \%$ \\
\hline Comunicação & $79 \%$ & $21 \%$ & $0 \%$ & $0 \%$ \\
\hline Dinamismo, iniciativa & $79 \%$ & $21 \%$ & $0 \%$ & $0 \%$ \\
\hline Flexibilidade & $79 \%$ & $21 \%$ & $0 \%$ & $0 \%$ \\
\hline Cultura da qualidade & $71 \%$ & $29 \%$ & $0 \%$ & $0 \%$ \\
\hline Organização & $54 \%$ & $46 \%$ & $0 \%$ & $0 \%$ \\
\hline $\begin{array}{l}\text { Capacidade trabalhar } \\
\text { sob pressão }\end{array}$ & $54 \%$ & $46 \%$ & $0 \%$ & $0 \%$ \\
\hline Criatividade & $50 \%$ & $50 \%$ & $0 \%$ & $0 \%$ \\
\hline Planejamento & $38 \%$ & $63 \%$ & $0 \%$ & $0 \%$ \\
\hline Visão sistêmica & $58 \%$ & $33 \%$ & $8 \%$ & $0 \%$ \\
\hline Tomada de decisão & $42 \%$ & $46 \%$ & $13 \%$ & $0 \%$ \\
\hline $\begin{array}{l}\text { Capacidade } \\
\text { empreendedora }\end{array}$ & $38 \%$ & $42 \%$ & $21 \%$ & $0 \%$ \\
\hline Liderança & $25 \%$ & $58 \%$ & $17 \%$ & $0 \%$ \\
\hline Negociação & $38 \%$ & $50 \%$ & $8 \%$ & $4 \%$ \\
\hline
\end{tabular}

Fonte: Elaboração própria (2017).

Foi possível evidenciar que a maioria das organizações consideram as competências humanas muito importantes e importantes no desempenho das funções dos profissionais de nível técnico. Os entrevistados, ao serem instigados a classificar as 15 competências humanas conforme seu grau de importância, apresentaram o seguinte resultado: $58,1 \%$ foram consideradas muito importantes, $37,2 \%$ foram consideradas importantes, $4,4 \%$ foram consideradas pouco importantes e $0,3 \%$ foi considerada sem importância. No último caso, a única competência que recebeu uma avaliação "sem importância" foi a competência Negociação.

As organizações pesquisadas sinalizaram que valorizam e consideram as competências humanas importantes, percebendo-se tal afirmativa na citação: "as competências humanas são muito importantes não adianta ter apenas conhecimento, é preciso também atitude, interesse, bom relacionamento" (010). Outra organização manifesta-se enfatizando que "profissionais com boas competências humanas tem muito mais capacidade de executar bem suas 
competências técnicas" (C14). Por último para reforçar a importância das competências humanas, uma organização afirma dar maior ênfase e relevância a elas no momento da seleção, se comparado com as competências técnicas, pois acredita ser mais fácil desenvolver competências técnicas do que humanas. Assim, se tiver que investir em desenvolvimento dentro da organização, o mesmo poderá ser voltado aos conhecimentos e competências técnicas.

Com base nas mesmas quinze competências de Gramigna (2007), as organizações pesquisadas definiram cinco competências que deveriam fazer parte do perfil de um bom profissional de nível técnico. No ranking de maior relevância, assim classificaram-se: $62,5 \%$ Relacionamento Interpessoal; 58,3\% Comunicação; $54,2 \%$ Motivação e energia para o trabalho; $50 \%$ Organização e 41,7\% Planejamento. Vejamos na Tabela 4:

Tabela 4: Ranking das competências humanas que devem fazer parte do perfil de um bom profissional de Nível Técnico

\begin{tabular}{|c|c|c|}
\hline Competência Humana & Ranking & $\%$ \\
\hline Relacionamento interpessoal & $1^{0}$ & $62,5 \%$ \\
\hline Comunicação & $2^{\circ}$ & $58,3 \%$ \\
\hline Motivação: energia para o trabalho & $3^{\circ}$ & $54,2 \%$ \\
\hline Organização & $4^{\circ}$ & $50,0 \%$ \\
\hline Planejamento & $5^{\circ}$ & $41,7 \%$ \\
\hline Capacidade de trabalhar sob pressão & $6^{0}$ & $37,5 \%$ \\
\hline Dinamismo, iniciativa & $7^{0}$ & $37,5 \%$ \\
\hline Flexibilidade & $8^{\circ}$ & $33,3 \%$ \\
\hline Visão sistêmica & $9^{\circ}$ & $33,3 \%$ \\
\hline Cultura da qualidade & $10^{\circ}$ & $29,2 \%$ \\
\hline Capacidade empreendedora & $11^{\circ}$ & $25,0 \%$ \\
\hline Criatividade & $12^{\circ}$ & $12,5 \%$ \\
\hline Negociação & $12^{\circ}$ & $12,5 \%$ \\
\hline Liderança & $13^{\circ}$ & $8,3 \%$ \\
\hline Tomada de decisão & $14^{\circ}$ & $4,2 \%$ \\
\hline
\end{tabular}

Fonte: Elaboração própria (2017).

Avaliando o Ranking das cinco competências humanas que obtiveram maior percentual, podemos relacioná-las com o nível estratégico operacional, no qual, usualmente, está inserido o profissional de nível técnico em uma organização. O nível operacional é constituído pela maior parte da mão de obra e, 
em se tratando de um técnico, suas atividades estão relacionadas à estrutura da organização, com predominância de trabalho em grupo, com prazos estipulados e tarefas específicas. Essa relação pode ser uma evidência das escolhas feitas pelas competências, onde é necessário profissionais que saibam se relacionar bem com os demais, motivados, comunicativos, organizados e que saibam planejar.

Em contrapartida, ao avaliar o mesmo rol de 15 competências humanas, foi possível observar que as competências que apareceram com menor incidência foram: Tomada de Decisão $(4,2 \%)$, seguida de Liderança $(8,3 \%)$, Negociação e Criatividade (12,5\%) e Capacidade Empreendedora (25\%). Se tomarmos por base a mesma relação inferida anteriormente, comparando com o nível estratégico organizacional, as competências relacionadas de menor ranking normalmente não caracterizam o nível operacional e consequentemente o profissional de nível técnico. Tomada de decisão, Liderança, Negociação e Capacidade empreendedora estão mais associadas ao nível tático e estratégico de uma organização.

Certamente tratar do assunto competências não é nada fácil, tão pouco seria avaliá-las. Entretanto, o estudo nos mostrou que tratar de competências humanas em profissionais de nível técnico nas organizações já tem sua relevância reconhecida pelas organizações. O profissional de nível técnico, ao buscar sua formação, precisa estar atento às demandas do mercado, considerando-o atravessado por grandes e frequentes transformações. Também necessita se inserir nesse conceito de atualização, aperfeiçoamento e busca constante pelo conhecimento e desenvolvimento de suas competências. Como relatado por uma das organizações: "o profissional precisa ter claro que a única constante é a mudança. Por isso, é importante ter um profissional que busque o conhecimento e que se atualize tanto nas questões humanas quanto técnicas" (O19).

\section{CONSIDERAÇÕES FINAIS}

Relatos de entrevistados evidenciam que as organizações atuais sofrem adaptações profundas e complexas, e que passaram a exigir a necessidade de novas formas de trabalho, que possa valorizar principalmente as competências humanas de sua equipe. Nosso interesse foi o de dimensionar e qualificar de que modo tais competências estão sendo percebidas pelas organizações nos profissionais de nível técnico.

Em uma avaliação do grau de importância das competências dos profissionais de nível técnico que atuam em organizações do Vale do Taquari, a maioria das organizações $(54,16 \%)$ atribui a mesma importância para competências humanas e técnicas, o que nos mostra que não há apenas uma única maneira de ser competente em relação a um problema ou a uma situação. Se as organizações são diferentes entre si, também as pessoas que nelas atuam 
precisam mobilizar suas competências de forma diferente para a consecução de determinado objetivo ou para a resolução de um problema específico.

Ao se referir ao profissional de nível técnico, as competências técnicas também apresentam seu nível de importância, considerado como principal por $12,50 \%$ das organizações. Vale lembrar que a avaliação de competências e a relação delas (competências técnicas e humanas), foi baseada em um profissional de nível técnico que traz reflexos característicos da concepção da educação profissional, quando o objetivo da educação era apenas qualificar o trabalhador para os "saberes técnicos", o que certamente influenciou no percentual. Contudo, $33,34 \%$ das organizações consideram as competências humanas até mais importantes do que as competências técnicas, o que nos faz acreditar que as organizações reconhecem a importância das competências humanas e até mesmo as relacionam com as estratégias organizacionais, já que elas contribuem para o alcance dos objetivos organizacionais.

As organizações, antes de buscar no mercado de trabalho profissionais capacitados e competentes, devem definir quais competências humanas são mais relevantes para o seu negócio, a fim de tornar essa busca mais efetiva. Na visão das organizações participantes desta pesquisa, o perfil de competências humanas contempla: relacionamento interpessoal, comunicação, motivação e energia para o trabalho, organização e planejamento. Segundo a avaliação dessas organizações, as competências elencadas devem fazer parte do perfil de um bom profissional de nível técnico, indiferente da titulação técnica por ele obtida. Certamente essas competências humanas irão fazer a diferença na hora de mobilizar os saberes desses profissionais e propiciarão um aprimoramento da conduta em termos de conhecimentos, habilidades e atitudes envolvidas no processo organizacional.

É sabido que há uma grande influência da aprendizagem sobre o desenvolvimento e mobilização das competências no ambiente organizacional (BOTERF, 2003; RUAS, 2008). Acreditamos que com um mercado em constantes transformações, a noção de competência fica ainda mais explicitada, o que, entretanto, não é suficiente para que consigamos desenvolvê-la. Os desafios na área da educação profissional ainda são grandes, já que os processos de qualificação não conduzem, por si só, ao aumento da competência dos profissionais.

Diante do resultado obtido, uma certeza foi evidenciada: competências humanas são importantes e, se associadas às competências técnicas, podem se tornar mais relevantes. Vale destacar, também, que não se pode excluir a necessidade de desenvolver as competências tidas como menos relevantes para o profissional de nível técnico, pois, como já visto, para desenvolver competências leva-se tempo e, com a finalidade de galgar novos níveis estratégicos, o profissional precisa estar em constante desenvolvimento e aprendizagem. Noção que também deve ser percebida pelas instituições educacionais.

O desenvolvimento de competências humanas na educação profissional precisa estar articulado com as necessidades das organizações. Não se pode admitir que o conceito competência na educação profissional seja evidenciado 
somente ao se tratar de questões legais. A educação profissional deve articular-se em prol de um objetivo maior, que é formar profissionais com competências técnicas ao mesmo tempo em que contribua para o desenvolvimento de suas competências humanas.

Torna-se necessário, então, pensar formas de flexibilizar o ensino, construindo processos que possam auxiliar na estruturação de propostas mais adaptadas às exigências das organizações, já que o desempenho delas depende de profissionais competentes. Tal modificação no ensino passa por contemplar novos conteúdos, mas, principalmente, não pode deixar de compreender o aluno como sujeito que deve ser capaz de pensar e se desenvolver com criatividade, trabalhar em equipe, enfrentar as adversidades e construir suas próprias crenças e valores. É preciso incorporar, nas ações do fazer pedagógico, condições e práticas por meio das quais as competências humanas possam ser desenvolvidas e estejam de acordo com as necessidades sinalizadas pelas organizações.

Acreditamos que a pesquisa possa servir de base para que as Instituições de Educação Profissional possam avaliar e, se for preciso, repensar sua forma de atuação, ao mesmo tempo poderão se valer das informações da pesquisa e investir no aprimoramento do ensino de Nível Técnico. Ressaltamos que o estudo, apesar de relevante, ainda é pequeno diante de muitas outras abordagens possíveis. Avaliar planos de cursos comparando com as competências sinalizadas pelo mercado pode ser um nicho a ser explorado nos próximos estudos. Nessa linha, podem surgir outras pesquisas que consigam embasar, discutir e fomentar 0 conceito de competências humanas na educação profissional.

\section{REFERÊNCIAS}

ANDRADE, M. M. de. Introdução à metodologia do trabalho científico. 6. ed. São Paulo: Atlas, 2003.

BARROS, A. J. da S.; LEHFELD, N. A. de S. Fundamentos de metodologia científica: um guia para a iniciação científica. 2. ed. Ampliada. São Paulo: Pearson Education do Brasil, 2000.

BARBOSA, E. F.; MOURA, D. G. Metodologias ativas de aprendizagem na Educação Profissional e Tecnológica. Boletim Técnico SENAC, Rio de Janeiro, v. 39 , n. 2, p. 48-67, maio/ago. 2013. Disponível em: <www.senac.br/media/42471/os_boletim_web_4.pdf>. Acesso em: 21 jul. 2017.

BRANDÃO, H. P.; ANDRADE J. E. B. Causas e efeitos da expressão de competências no trabalho: para entender melhor a noção de competência. Revista de Administração Mackenzie, v.8, n.3, p. 32-49, 2007. Disponível em: $<$ http://editorarevistas.mackenzie.br/index.php/RAM/article/view/136>. Acesso em: 13 jun. 2017.

BRASIL. Lei № 9.394, de 20 de dezembro de 1996. Estabelece as diretrizes e bases da educação nacional. Disponível em: 
<http://www.planalto.gov.br/ccivil_03/leis/L9394.htm>. Acesso em: 13 jun. 2017.

Lei № 11.741, de 16 de julho de 2008. Estabelece as diretrizes e bases da educação nacional, para redimensionar, institucionalizar e integrar as ações da educação profissional técnica de nível médio, da educação de jovens e adultos e da educação profissional e tecnológica. Disponível em: <http://www.planalto.gov.br/ccivil_03/_Ato2007-2010/2008/Lei/L11741.htm>. Acesso em: 13 jun. 2017.

Parecer CNE/CEB no 16, de 05 de outubro de 1999. Diretrizes Curriculares Nacionais para a Educação Profissional de Nível Técnico. Disponível em:<http://portal.mec.gov.br/cne/arquivos/pdf/1999/pceb016_99.pdf>. Acesso em: 21 jul. 2017.

Parecer CNE/CEB no 11, de 09 de maio de 2012. Diretrizes Curriculares Nacionais para a Educação Profissional de Nível Médio. Disponível em: < http://portal.mec.gov.br/index.php?option=com_docman\&view=download\&alias $=10$ 804-pceb011-12-pdf\&category_slug=maio-2012-pdf\&ltemid=30192>. Acesso em: 21 jul. 2017.

Resolução CNE/CEB no 6, de 20 de setembro de 2012. Define Diretrizes Curriculares Nacionais para a Educação Profissional Técnica de Nível Médio. Disponível em:

http://portal.mec.gov.br/index.php?option=com_docman\&view=download\&alias=11 663-rceb006-12-pdf\&category_slug=setembro-2012-pdf\&ltemid=30192>. Acesso em: 19 jun. 2017.

CHEMIN, B. F. Manual da Univates para trabalhos acadêmicos: planejamento, elaboração e apresentação. 3. ed. Lajeado: Univates, 2015. E-book. Disponível em: <www.univates.br/biblioteca>. Acesso em: 07 jun. 2017.

DADOY, $M$. As noções de competência e competência à luz das transformações na gestão da mão-de-obra. In: TOMASI, A. (Org.). Da qualificação à competência: Pensando o século XXI. Campinas: Papirus, 2004. p. 105-142.

DEPRESBITERIS, L. Competências na Educação Profissional - É possível avaliá-las? Boletim Técnico do Senac, Rio de Janeiro, v.31, n.2, mai./ago. 2005. Disponível em < http://www.bts.senac.br/index.php/bts/article/view/333>. Acesso em: 03 jul. 2017.

DUTRA, J. S. Competências: conceitos e instrumentos para a gestão de pessoas na empresa moderna. 1. ed. 5. reimpr. São Paulo: Atlas, 2008.

(Org.). Gestão por competências: Um modelo avançado para o gerenciamento de pessoas. São Paulo: Editora Gente, 2001.

FLEURY, A.; FLEURY, M. T. L. Estratégias empresariais e formação de competências. 3. ed. São Paulo: Atlas, 2004.

(Org.). Gestão estratégica do conhecimento: integrando aprendizagem, conhecimento e competências. 1. ed. 5.reimp. São Paulo: Atlas, 2008. 
GRAMIGNA, M. R. Modelo de Competências e Gestão dos Talentos. 2.ed. São Paulo: Pearson Prentice Hall, 2007.

HAMEL, G.; PRAHALAD, C. K. Competindo pelo futuro: estratégias inovadoras para obter o controle do seu setor e criar os mercados de amanhã. Rio de Janeiro: Campus, 1995.

KULLER, J. A. Educação Profissional e Compromisso com o Desenvolvimento de Competências Profissionais. Boletim Técnico do Senac, Rio de Janeiro, v.39, n.1, jan./abr. 2013. Disponível em < http://www.bts.senac.br/index.php/bts/article/view/141/126>. Acesso em: 25 jul. 2017.

LE BOTERF, G. Desenvolvendo a Competência dos Profissionais. Tradução: Patrícia Chittoni Ramos Reuillard. 3. ed. Porto Alegre: Artmed, 2003.

LERNER, W. Competência é essencial na administração. São Paulo: Global, 2002.

MALHOTRA, N. K. Pesquisa de marketing: uma orientação aplicada. 4. ed. Porto Alegre: Bookman, 2006.

PERRENOUD, P. Construir as competências desde a escola. Porto Alegre: Artmed, 1999.

RUAS, R. Desenvolvimento de competências gerenciais e contribuição da aprendizagem organizacional. In: FLEURY, M. T. L; OLIVEIRA JR, M. de M. (Org.). Gestão estratégica do conhecimento: integrando aprendizagem, conhecimento e competências. 1. ed. reimp. São Paulo: Atlas, 2008. p. 242-269.

TOMASI, A. (Org.). Da Qualificação à Competência: Pensando o século XXI. Campinas: Papirus, 2004.

ZARIFIAN, P. Objetivo competência: por uma nova lógica. São Paulo: Atlas, 2001. 